\title{
CARBOHYDRATE RELEASE BY A SUBTROPICAL STRAIN OF SPONDYLOSIUM PYGMAEUM (ZYGNEMATOPHYCEAE): INFLUENCE OF NITRATE AVAILABILITY AND CULTURE AGING ${ }^{1}$
}

\author{
Fernanda Reinhardt Piedras \\ Pós-graduação em Oceanografia Biológica, Instituto de Oceanografia, Universidade Federal de Rio Grande- FURG, Av. Italia, Km 8, \\ Rio Grande, RS 96201-900, Brasil

\section{Paulo Roberto Martins Baisch, Maria Isabel Corrêa da Silva Machado} \\ Laboratório de Oceanografia Geológica Instituto de Oceanografia, Universidade Federal de Rio Grande- FURG, Av. Italia, Km 8, \\ Rio Grande, RS 96201-900, Brasil \\ Armando Augusto Henriques Vieira \\ Departamento de Botanica, Unversidade Federal de Sao Carlos, Via Washington Luis, Km 235, Sao Carlos, SP 13565-905, Brasil
}

\author{
and Danilo Giroldo ${ }^{2}$
}

Laboratório de Botânica Criptogâmica, Instituto de Ciências Biológicas, Universidade Federal de Rio Grande - FURG, Av. Italia, Km 8, Rio Grande, RS 96201-900, Brasil

This paper describes the influence of nitrate availability on growth and release of dissolved free and combined carbohydrates (DFCHOs and DCCHOs) produced by Spondylosium pygmaeum (Cooke) W. West (Zygnematophyceae). This strain was isolated from a subtropical shallow pond, located at the extreme south of Brazil (Rio Grande, RS). Experiments were carried out in batch culture, comparing two initial nitrate levels $(10 / 100 \mu \mathrm{M})$ in the medium. Growth was monitored by direct microscopic cell counts and chl $a$ content. Nitrate consumption was determined by ion chromatography, while the production of extracellular carbohydrates was monitored by the phenol-sulfuric method. The monosaccharide compositions of DFCHOs and DCCHOs were determined in each growth phase by HPLC with pulse amperometric detection (HPLCPAD). At the end of the experiment, the total composition of extracellular polysaccharide (EPS) molecules $>12 \mathrm{kDa}$ was determined by gas chromatography. Nitrate availability had no influence on $S$. pygmaeum cell density at any phase. On the other hand, chl $a$ content decreased after a few days growth when the availability of nitrate was restricted, but continued to rise when nitrate was plentiful. Also, nitrate depletion was faster at $10 \mu \mathrm{M}$ nitrate. No influence of the growth phase or nitrate availability on the total carbohydrates (TDCHOs) released per cell was observed. Only DCCHOs were released by $S$. pygmaeum, and the composition varied between growth phases, especially at lower nitrate

\footnotetext{
${ }^{1}$ Received 25 June 2009. Accepted 18 November 2009.

${ }^{2}$ Author for correspondence: e-mail dmbgirol@furg.br.
}

availability. EPS molecules $>12 \mathrm{kDa}$ were composed mainly of xylose, fucose, and galactose, as for other desmids. However, a high $\mathrm{N}$-acetyl-glucosamine content was found, uniquely among desmid EPSs.

Key index words: carbohydrate; desmid; growth; nitrate; Spondylosium

Abbreviations: Ara, arabinose; DCCHO, dissolved combined carbohydrate; DFCHO, dissolved free carbohydrate; EPS, extracellular polysaccharide; Fuc, fucose; Gal, galactose; GalA, galacturonic acid; GalNAc, $N$-acetylgalactosamine; Glc, glucose; GlcA, glucuronic acid; GlcNAc, $N$-acetylglucosamine; Man, mannose; Rha, rhamnose; TDCHO, total dissolved carbohydrate; Xyl, xylose

EPSs are the main fraction of dissolved organic carbon released by freshwater phytoplankton (Paulsen and Vieira 1994), and such production is a significant source of carbohydrates in natural waters (Biersmith and Benner 1998). However, few studies have attempted to characterize the composition of carbohydrates released by phytoplankton, comparing to the large variety of species whose products have not been studied yet (Giroldo and Vieira 2005).

Production of EPSs is a conspicuous process among desmids, because of the formation of mucilaginous capsules, as well as the release of dissolved polysaccharides (Domozych 2005). EPS release is the result of the action of physiological processes on the allocation of photoassimilated carbon (Vieira and Myklestad 1986) and is associated with Golgi vesicle production (Domozych et al. 2007). Mucilage 
capsules have been reported to result from diverse adaptative strategies, including buoyancy improvement, grazing reduction, and selective permeability (Reynolds 2007). Although the formation of a capsule itself is not influenced by nutrient availability in Staurodesmus convergens (Gouvêa et al. 2002), the thickness and texture of the mucilage formed vary with the environment (Reynolds 2007).

Dissolved polysaccharide release is also a process described as depending on nutrient availability (Myklestad 1995). Nitrogen and phosphorus deficiency increases the EPS release rate in many species (Lombardi et al. 1998, Giroldo and Vieira 2005). Excess light and nutrient depletion together decrease cytokinesis while photosynthesis is still active, leading to an excess of photoassimilated carbon (Fogg 1983), which is diverted into carbohydrate release. Under such stress conditions, excess electrons accumulating in the photosynthetic electron transport chain (PETC) may induce overproduction of reactive oxygen species, causing photoinhibition and damage to membranes. The synthesis of carbohydrate, or triacylglycerols, consumes NADPH generated by the PETC, relaxing the overreduced PETC under stress conditions. Moreover, in such conditions, carbohydrate release acts as a protection of the photosynthetic apparatus (Smith and Underwood 2000) and also stimulates bacterial growth associated with the dissolved organic matter (DOM) excreted by phytoplankton (Giroldo et al. 2007). Bacterial growth on algal DOM as a substrate increases nutrient remineralization and, consequently, may promote phytoplankton growth by the coevolution of complex plankton communities (Wood and Van Valen 1990).

More recently, EPS production has been related to the formation of transparent exopolymer particles, responsible for the formation of large aggregates in marine environments (Alldredge et al. 1993, Passow 2002). Such particles play an important part in diatom bloom coagulation, providing an adaptative function for the cells of a declining bloom, which drop down to depths with better nutrient conditions than the depleted surface (Passow et al. 1994). Although this process was proposed to explain large aggregates and bloom dynamics in the marine environment, the significance of such a process in freshwater has also been pointed out by some authors (Vieira et al. 2006, 2008).

The aim of this study was to determine the influence of nitrate availability and aging of the culture on the physiology of a subtropical strain of $S$. pygmaeum. Growth, nitrate utilization, and carbohydrate release were studied to add to current knowledge of desmid physiology, as well as to improve the understanding of carbohydrate release. Such data are also required to determine the physiological characteristics of a species, to contribute to future functional classifications of phytoplankton, a successful approach employed to describe population fluctua- tions and occurrence of species in natural waters (Reynolds et al. 2002, Salmaso and Padisak 2007).

\section{MATERIALS AND METHODS}

Organism and culture conditions. S. pygmaeum (Desmidiaceae) is one of the smaller filamentous desmids (Croasdale et al. 1983). A subtropical strain (FURGZY006) was isolated from a small (surface area $1,000 \mathrm{~m}^{2}$ ), shallow (average depth $1.8 \mathrm{~m}$ ) pond, located in the Carreiros campus of the Federal University of Rio Grande in the extreme south of Brazil $\left(32^{\circ} 04^{\prime} 18^{\prime \prime} \mathrm{S}\right.$ and $52^{\circ} 09^{\prime} 57^{\prime \prime} \mathrm{W}$ ). The cells are elliptical in side view and subelliptical in top view, with a smooth cell wall. The isolated cells $(N=50)$ were $6.6 \pm 0.9 \mu \mathrm{m}$ long and $6.5 \pm 0.3 \mu \mathrm{m}$ broad with a $3.6 \pm 0.6 \mu \mathrm{m}$ isthmus. Axenic cultures were obtained by micromanipulation and several washes under the microscope (mod. CX41F; Olympus, Tokyo, Japan). Cultures were maintained axenically in WC medium (Guillard and Lorenzen 1972) at $\mathrm{pH}$ 7.0, in 12:12 light:dark (L:D) cycles with $100 \mu \mathrm{mol} \cdot \mathrm{m}^{-2} \cdot \mathrm{s}^{-1}$ of irradiance and temperature controlled at $25^{\circ} \mathrm{C} \pm 1{ }^{\circ} \mathrm{C}$.

Experimental design. Triplicate experiments were carried out with $S$. pygmaeum in batch culture, using media based on WC medium, with sodium nitrate as the sole nitrogen source, reduced from the original $1,000 \mu \mathrm{M}$ to 10 and $100 \mu \mathrm{M}$. A $150 \mathrm{~mL}$ culture of $S$. pygmaeum in WC medium, at the exponential growth phase $\left(30 \mathrm{~d}, 10^{7} \mathrm{cell} \cdot \mathrm{mL}^{-1}\right)$, was centrifuged $(5 \mathrm{~min}, 3,000 \mathrm{~g})$ in a Sigma 2 K15 centrifuge (Osterode am Harz, Germany), washed, and resuspended in nitrogen-free $\mathrm{WC}$ medium $(600 \mathrm{~mL})$. This was kept under starvation for $7 \mathrm{~d}$ in the culture conditions described above, to exhaust most of the intracellular nitrogen reserves. Aliquots of $30 \mathrm{~mL}$ of the starved culture were inoculated in six $1 \mathrm{~L}$ Erlenmeyer flasks with $600 \mathrm{~mL}$ of WC medium each, at each of the nitrate test levels. In parallel, $100 \mathrm{~mL}$ aliquots of the starved culture were inoculated in duplicate $4 \mathrm{~L}$ carboys with $3.5 \mathrm{~L}$ of WC medium and the respective nitrate concentrations. The experiment continued until stationary growth phases had been observed at both nitrate levels.

An aliquot of $30 \mathrm{~mL}$ was sampled from each $1 \mathrm{~L}$ Erlenmeyer flask at intervals of 48-72 $\mathrm{h}$ to measure growth by direct microscopic cell counts and chl a content determination. Subsamples $(4 \mathrm{~mL})$ were fixed and stained with Lugol's solution before cells were counted in a hemocytometer improved Neubauer (Brand, Wertheim, Germany). An $11 \mathrm{~mL}$ aliquot was centrifuged for $20 \mathrm{~min}$ at $3,745 \mathrm{~g}$, and the supernatant used to determine total extracellular carbohydrate (Dubois et al. 1956). To determine chl $a$ content, the cell pellet was extracted for $24 \mathrm{~h}$ in $10 \mathrm{~mL}$ methanol in the dark at $-4^{\circ} \mathrm{C}$ and centrifuged again for $10 \mathrm{~min}$ at $3,745 \mathrm{~g}$. The supernatants were read in a Q798-U spectrophotometer (Quimis, Diadema, Brazil) at 665 and $750 \mathrm{~nm}$, and chl $a$ content was calculated, using the coefficient proposed by Mackinney (1951). In the periodic samples of culture supernatant, the dissolved carbohydrates were estimated by HPLC with pulse amperometric detection (PAD), and the extracellular concentration of the nitrogen source (nitrate) was determined by ion chromatography with conductivity detection. All the chromatographic analyses are described in the next section.

A first-order decay equation (eq. 1) was used to describe extracellular nitrate utilization. Such equations assume the reaction rate to be proportional to the reagent concentration and define a rate constant (decay coefficient) whose unit is $\mathrm{d}^{-1}$ :

$$
A_{t}=A_{0} \mathrm{e}^{-k t}
$$

where $A_{\mathrm{t}}=$ nitrate concentration $(\mu \mathrm{M}) ; A_{0}=$ initial nitrate concentration $(\mu \mathrm{M}) ; k=$ decay coefficient $\left(\mathrm{d}^{-1}\right) ; \mathrm{e}=$ base of natural logarithms; $t=$ time $(\mathrm{d})$.

The variation of nitrate concentration with time was used to determine the decay coefficient. To this end, a curve defined 
by equation 1 was fitted to the data by nonlinear regression (Levenberg-Marquardt algorithm), as described by Press et al. (1993). This model was used only to compare patterns of nitrate depletion during batch culture growth, and the first order equation was chosen for its simplicity.

The whole volume of each $3.5 \mathrm{~L}$ culture was filtered through a glass fiber filter of $0.7 \mu \mathrm{m}$ pore size (Whatman $\mathrm{GF} / \mathrm{F}$, Maidstone, UK) under low vacuum. The filtrate was freezedried and then resuspended in distilled water $(100 \mathrm{~mL})$ and dialyzed against distilled water in dialysis tubes with a 12$14 \mathrm{kDa}$ molecular weight cutoff. Two drops of toluene were added to the tubes to prevent bacterial contamination. The dialyzed material was freeze-dried and stored at $-4^{\circ} \mathrm{C}$ under nitrogen to perform gas chromatography EPS analysis, as described in the next section.

Chromatographic analysis. Composition of polymeric and free carbohydrates produced during each growth phase was examined by HPLC-PAD (Gremm and Kaplan 1997). The extracellular dissolved carbohydrates were divided into two fractions before analysis: TDCHOs and DFCHOs. DCCHOs were determined by subtracting DFCHOs from TDCHOs. The DFCHO samples were injected directly into the HPLC system, while TDCHOs were hydrolyzed (Gremm and Kaplan 1997) prior to injection. The HPLC-PAD system was a Dionex DX500 (Sunnyvale, CA, USA), including a GP40 gradient pump (PEEK tubing), an ED40 electrochemical detector and an LC5 manual injector with a Rheodyne 9125 valve and a $25 \mu \mathrm{L}$ PEEK sample loop. The ED40 detector was equipped with an amperometric flow cell, a gold working electrode, and an $\mathrm{Ag} / \mathrm{AgCl}$ reference electrode. The monosaccharides were separated on a PA-10 (Dionex) anion-exchange analytical column $(4 \times 250 \mathrm{~mm})$, fitted with a matching guard column $(4 \times 50 \mathrm{~mm})$. The eluents used were $18 \mathrm{mM} \mathrm{NaOH}$ for separation and $200 \mathrm{mM} \mathrm{NaOH}$ for column recovery, flowing at $1 \mathrm{~mL} \cdot \mathrm{min}^{-1}($ Gremm and Kaplan 1997). Uronic acid was eluted with a sodium acetate gradient, after the elution of neutral sugars (Wicks et al. 1991).

Extracellular nitrate concentration was determined by high performance ion chromatography (HPIC) with conductivity detection. We used a Metrohm ${ }^{8}$ (Herisau, Switzerland) system with an anionic column of polyvinyl alcohol with chemical suppression of background conductivity and fitted with the matching guard column (Metrosep A Supp 5-100, $4.0 \times 100 \mathrm{~mm}$ ). Eluents were sodium bicarbonate and carbonate $\left(1.7 \mathrm{mM} \quad \mathrm{NaHCO}_{3}\right.$ and $\left.18 \mathrm{mM} \quad \mathrm{Na}_{2} \mathrm{CO}_{3}\right)$ flowing at $0.6 \mathrm{~mL} \cdot \mathrm{min}^{-1}$, at $20^{\circ} \mathrm{C}$ and $6.1 \mathrm{MPa}$. All subsamples for HPIC and HPLC-PAD analysis were passed through glass fiber filters with $0.7 \mu \mathrm{m}$ pores (Whatman $\mathrm{GF} / \mathrm{F}$ ) prior to analysis.

Monosaccharide composition of isolated EPSs $(>12 \mathrm{kDa})$ was determined by gas chromatography (GC) of the trimethylsilylated derivatives of the methyl glycosides, obtained by methanolysis with $4 \mathrm{M} \mathrm{HCl}$ in methanol at $80^{\circ} \mathrm{C}$ for $24 \mathrm{~h}$ (Reinhold 1972, Barsett et al. 1992). Mannitol was used as an internal standard. GC analysis was performed on a Hewlett-Packard 5890 Series II gas chromatograph equipped with a DB-5 (J and W Scientific, Folsom, CA, USA) fused silica capillary column $(30 \mathrm{~m} \times 0.32 \mathrm{~mm})$ and a hydrogen flame ionization detector (FID). Helium was used as the carrier gas $\left(2.5 \mathrm{~mL} \cdot \mathrm{min}^{-1}\right)$. Nitrogen flow was $28 \mathrm{~mL} \cdot \mathrm{min}^{-1}$; hydrogen, $30 \mathrm{~mL} \cdot \mathrm{min}^{-1}$; and air, $360 \mathrm{~mL} \cdot \mathrm{min}^{-1}$. The injector temperature was $260^{\circ} \mathrm{C}$, and the column temperature was initially set to $140^{\circ} \mathrm{C}$ and programmed to rise at $1^{\circ} \mathrm{C} \cdot \mathrm{min}^{-1}$ to $170^{\circ} \mathrm{C}$, and then at $6^{\circ} \mathrm{C} \cdot \mathrm{min}^{-1}$ from $170^{\circ} \mathrm{C}$ to $250^{\circ} \mathrm{C}$. The detector temperature was maintained at $300^{\circ} \mathrm{C}$.

\section{RESULTS}

Figure 1 shows the growth and nitrate utilization in a culture of $S$. pygmaeum $>36 \mathrm{~d}$. There was no sig-

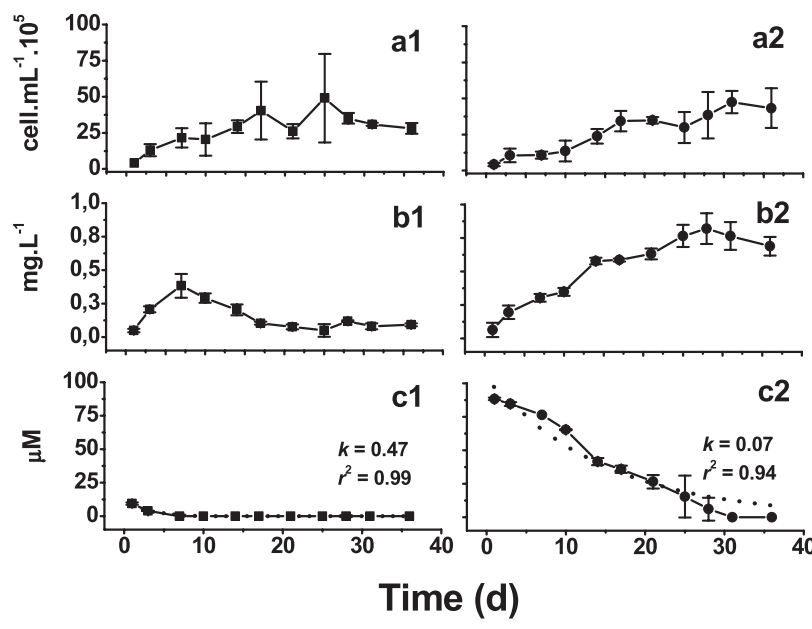

FIG. 1. Growth of Spondylosium pygmaeum determined as (a) cell density and (b) chl $a$, and (c) nitrate utilization during $36 \mathrm{~d}$ cultures in (1) 10 and (2) $100 \mu \mathrm{M}$ nitrate. Bars show standard deviation $(N=3), k=$ decay coefficient in $\mathrm{d}^{-1}$.

nificant change in cell density with aging of the culture at either nitrate concentration (Fig. 1, al and a2). Also, there was no significant difference between the maximum cell densities at the lower and higher nitrate levels. In contrast, the chl $a$ content peaked early and then fell steadily as the culture aged, at $10 \mu \mathrm{M}$ nitrate (Fig. 1b1), while at $100 \mu \mathrm{M}$ nitrate, chl $a$ continued to rise for a much longer time, reaching a higher maximum (Fig. 1b2). Besides, the growth profiles were substantially different when measured as cell density and chl $a$ content, suggesting that pigment degradation occurs during aging of the cell population at low nitrate availability. Nitrate was exhausted after 7 and $31 \mathrm{~d}$ at the lower and higher nitrate concentrations, respectively (Fig. 1, c1 and c2). Although $S$. pygmaeum removed $100 \mu \mathrm{M} \mathrm{NO}_{3}{ }^{-}$at the higher nitrate concentration and much less at the lower, this was mainly used to increase the chl $a$ content, rather than cell division, since the cell density profile was similar at the two levels of nitrate, in contrast to chl $a$ profile, which differed greatly. The rate constant for removal of nitrate was higher at $10 \mu \mathrm{M}$ $(k=0.47)$ than at $100 \mu \mathrm{M}(k=0.07)$ initial nitrate (Fig. 1, c1 and c2). This difference correlated with the biomass duplication time. The cell density doubled in $4.9 \mathrm{~d}$ at low nitrate and in $5.3 \mathrm{~d}$ at the higher nitrate level.

Figure 2 shows the total release of carbohydrates per cell and the rate of carbohydrate release per cell. Extracellular carbohydrate released per cell (Fig. 2, a1 and a2) was constant during most of the growth, and the large amount released per cell in the first $3 \mathrm{~d}$ at both nitrate levels was probably due to cell adaptation to the culture medium. There was no significant difference in the release of total carbohydrates per cell at $10 \mu \mathrm{M}$ and $100 \mu \mathrm{M}$ nitrate. 


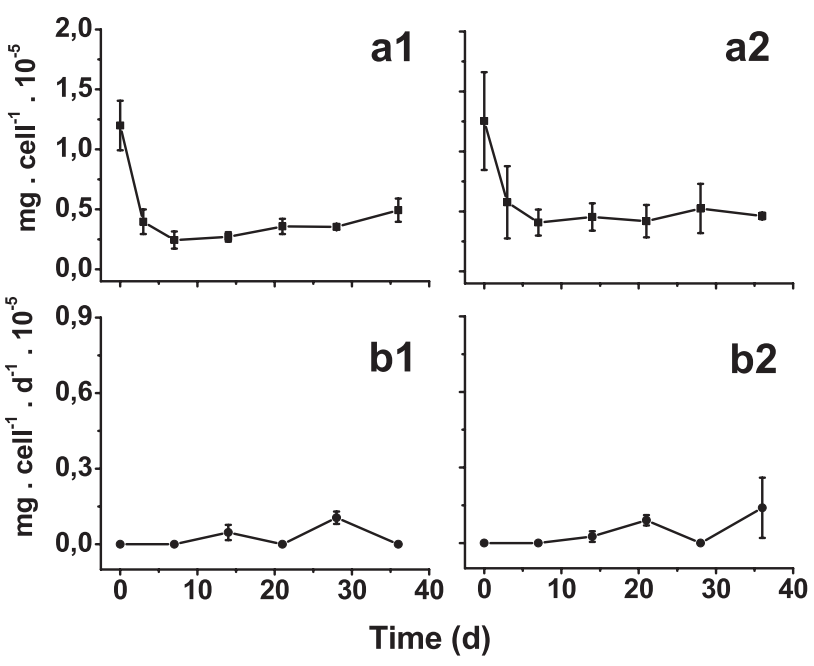

Fig. 2. (a) Total carbohydrate release per cell and (b) rate of carbohydrate release per cell per day of Spondylosium pygmaeum, during $36 \mathrm{~d}$ batch cultures in (1) 10 and (2) $100 \mu \mathrm{M}$ nitrate. Bars show standard deviation $(N=3)$.

Also, S. pygmaeum cells released total carbohydrates at a rate proportional to the growth rate, since no significant increase in the release rate per cell was detected during the experiment (Fig. 2, b1 and b2).

Only DCCHOs were released by $S$. pygmaeum, since no free carbohydrates were detected during the growth. Figure 3 shows the composition of the DCCHOs, analyzed by HPLC-PAD, released in the exponential and stationary growth phases at both nitrate contents. Fucose (Fuc), rhamnose (Rha) and/or $\mathrm{N}$-acetylgalactosamine (GalNAc), arabinose (Ara), N-acetylglucosamine (GlcNAc), galactose (Gal), glucose (Glc), mannose (Man) and/or xylose (Xyl), galacturonic acid (GalA), and glucuronic acid (GlcA) were identified at both nitrate levels. Man/Xyl and Rha/GalNAc were not properly separated by the PA10 column and were analyzed as single peaks.

The main DCCHO monosaccharide components varied with culture conditions. Fuc, Gal, Glc, Man/ $\mathrm{Xyl}$, and GlcA were the main DCCHO components at the lower nitrate level. Rha/GalNAc and Ara were present in similar proportions to Fuc, Gal, Glc, and Man/Xyl at the higher nitrate level, while GlcA and GlcNAc were in lower quantities than the other components in this culture.

Significant differences between the cultures grown in $10 \mu \mathrm{M}$ and $100 \mu \mathrm{M}$ nitrate were found only in the percentage of GalA, which was higher in the former than in the latter. Significant differences between exponential and stationary growth phases were more pronounced in $10 \mu \mathrm{M}$ nitrate. The percentages of Gal and Glc decreased in the stationary growth phase at lower nitrate concentration (ANOVA: $P=0.018$ and $P=0.032$, respectively), while percent GlcA increased in the stationary phase (ANOVA: $P=0.025$ ). Besides the significant differences, Figure 3 indicates that DCCHO composition

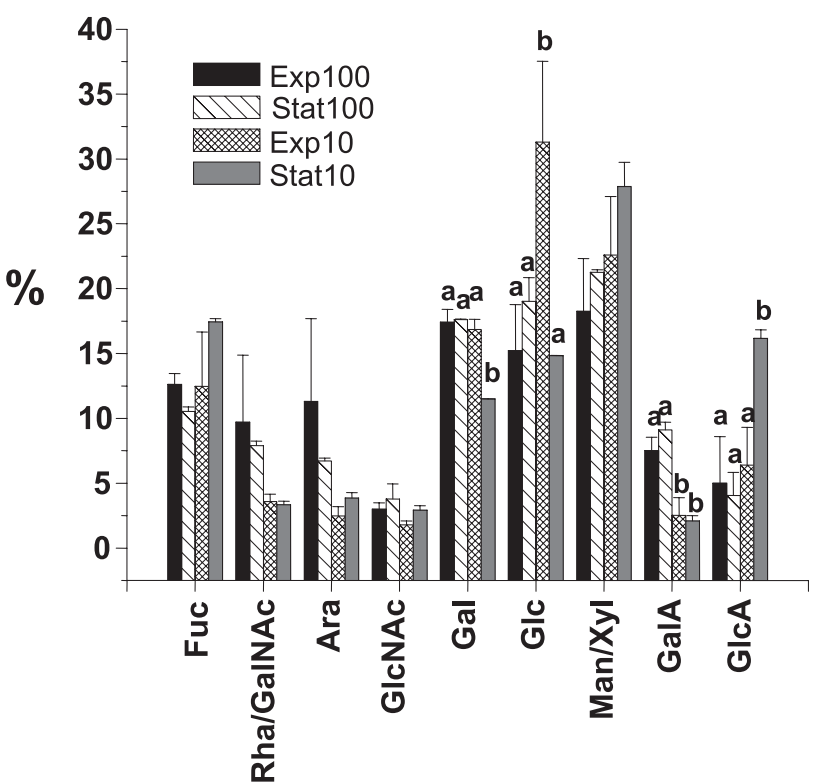

FIG. 3. Composition of dissolved combined carbohydrates (DCCHO) released by Spondylosium pygmaeum in the exponential (Exp) and stationary (Stat) growth phases, when cultured in 10 and $100 \mu \mathrm{M}$ nitrate. Significant differences between the cultures are indicated by different letters on each monosaccharide. No letter means no significant difference. Bars show standard deviation $(N=3)$. Ara, arabinose; Fuc, fucose; Gal, galactose; GalA, galacturonic acid; GalNAc, N-acetylgalactosamine; Glc, glucose; GlcA, glucuronic acid; GlcNAc, N-acetylglucosamine; Man, mannose; Rha, rhamnose; Xyl, xylose. Mannose/xylose (Man/Xyl) and rhamnose/ $N$-acetylgalactosamine (GalNAc) are not properly separated by PA10 column.

was altered mainly by long stationary growth periods and aging of the culture.

Figure 4 shows the composition of the EPSs isolated at the end of the experiment, at both nitrate concentrations, analyzed by gas chromatography. As the material was dialyzed to remove molecules $<12 \mathrm{kDa}$, its composition was significantly different from that in Figure 3. This dialyzed EPS material was mainly composed of Xyl, Fuc, GlcNAc, and Gal, with minor proportions of Ara, Glc, Rha, Man, GalNAc, GalA, and GlcA. Only the proportions of Xyl and Man were significantly increased at the lower nitrate content, while Ara, Rha, Gal, Glc, and GlcNAc were decreased by nitrate depletion. This result confirms the influence of nitrate availability on the composition of saccharide polymers excreted by $S$. pygmaeum. A comparative analysis of the two sets of chromatographic results indicates the production of a low-molecular-weight polysaccharide $(<12 \mathrm{kDa})$ rich in GlcA, which was released in nitrate-depleted conditions.

\section{DISCUSSION}

Nitrogen is one of the most important elements controlling the phytoplankton population in natural water (Herndon and Cochlan 2007), mainly because 


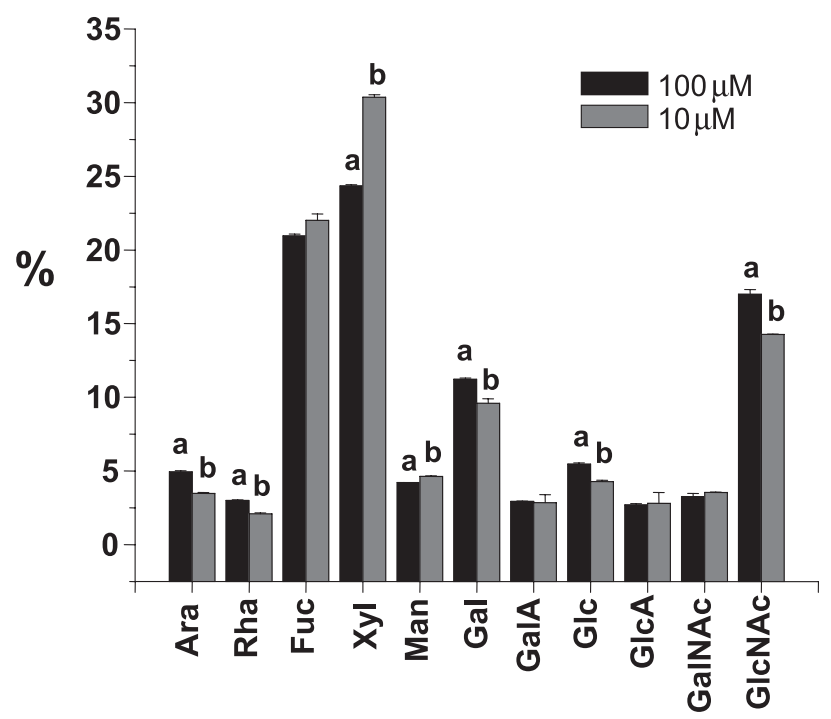

FIG. 4. Composition of extracellular polysaccharides (EPSs) of molecular weight $>12 \mathrm{kDa}$ released by Spondylosium pygmaeum during $36 \mathrm{~d}$ cultures in 10 and $100 \mu \mathrm{M}$ nitrate. Significant differences between the cultures are indicated by different letters on each monosaccharide. No letter means no significant difference. Bars show standard deviation $(N=3)$. Ara, arabinose; Fuc, fucose; Gal, galactose; GalA, galacturonic acid; GalNAc, $N$-acetylgalactosamine; Glc, glucose; GlcA, glucuronic acid; GlcNAc, N-acetylglucosamine; Man, mannose; Rha, rhamnose; Xyl, xylose.

of its incorporation into nucleic acids and proteins. The main nitrogen sources for phytoplankton growth can be inorganic, such as nitrate, nitrite, and ammonium, or organic compounds, such as urea, amino acids, and peptides (Vieira and Klaveness 1986, Padisák 2004). Our results indicated that growth at differing levels of nitrate availability influenced physiological characteristics of S. pygmaeum, especially the chl $a$ content and EPS composition.

Nutrient-limited conditions did not provoke any increase in the extracellular carbohydrate production by $S$. pygmaeum, in either the lower or higher nitrate experiment. Except in the first $3 \mathrm{~d}$ of both experiments, when cells were acclimating to the culture medium (Lombardi et al. 1998), the carbohydrate released per cell was constant throughout both experiments. Also, the rate of release of carbohydrate per day showed no significant increase during the whole experiment, under all conditions. This finding indicates that this strain grew at a rate proportional to the rate of release of carbohydrates, in all growth phases and nitrate levels. Our results further show that photoassimilated carbon excess (Fogg 1983) under nutrient-limited conditions was not diverted to carbohydrate release, in contrast to results found by several authors for other desmids (Lombardi et al. 1998, Giroldo and Vieira 2005).

$S$. pygmaeum showed a high nitrogen storage capacity, since cell density did not fall, even during a 30 d stationary growth phase. Also, its nitrate requirements for growth were low, since the maximum cell density was similar at both nitrate concentrations. The nitrate removed from the medium, but not used for growth, was probably stored and used for pigment synthesis, indicating an adaptation of this desmid to oligotrophic water. Cell pigment (chl) degradation was observed under depleted conditions (Fig. 1), despite maintenance of the population density. During this process, no increase in extracellular carbohydrate production by S. pygmaeum was observed. This pigment degradation probably supplied nitrogen for growth and prevented the photosynthetic apparatus from being damaged by electron excess in nutrient-limited conditions (Abdullahi et al. 2006). Although nutrient depletion had no quantitative effect on extracellular carbohydrate production, as reported before (Gouvêa et al. 2002), our results showed that the composition of such carbohydrates was significantly influenced by nitrate availability. Only DCCHOs were released by $S$. pygmaeum, the main constituents being Fuc, Gal, Glc, Man/Xyl, and GlcA. Xyl, Fuc, GlcNAc, and Gal represented most of the monosaccharides of the EPSs of molecular weight $>12 \mathrm{kDa}$. In general, the carbohydrate polymer composition was altered in nutrient-limited conditions, indicating that nutrient depletion had influenced biosynthetic pathways. The percentage of GlcA in DCCHOs up to $12 \mathrm{kDa}$ increased at the lower nitrate concentration in the stationary growth phase but did not do so at higher nitrate availability or in the larger EPSs. This observation suggests that an oligosaccharide or small polysaccharide rich in GlcA was produced during the long stationary phase under $\mathrm{N}$ depletion, at the lower nitrate level. This monosaccharide has been linked to high reactivity, besides metal binding (Freire-Nordi et al. 2005), indicating that this result may reflect a physiological strategy to increase competitiveness in nutrient-limited situations. Also, N depletion decreased the proportion of amino sugars, especially in the larger EPSs, probably due to the lack of nitrate. However, even in nitratedepleted medium, such amino sugars were maintained in both smaller and larger polymeric carbohydrates.

Similar EPS composition variation during the growth phases has been reported before (Giroldo and Vieira 2005), and the S. pygmaeum polymer carbohydrate composition is similar to other planktonic desmids. EPSs from Spondylosium panduriforme (Paulsen and Vieira 1994) and Micrasterias furcata (Lombardi et al. 1998), with high Gal content, and Hyalotheca dissiliens (Vieira and Paulsen 1994), Staurodesmus convergens (Gouvêa et al. 2002), and Staurastrum orbiculare (Giroldo et al. 2005), with high Fuc content, are desmid EPSs with similar features to that of $S$. pygmaeum. Also, the proportion of uronic acids is similar to that of the planktonic desmids mentioned above, as well as benthonic desmids such as Pleurotaenium trabecula (Kiemle et al. 2007). On the other hand, such high Xyl content $(>20 \%)$ in the larger EPSs is rarely reported for planktonic 
desmids, such as Micrasterias furcata (Lombardi et al. 1998), but it is commoner in benthic desmids, such as Penium margaritaceum (Domozych 2005) and Pleurotaenium trabecula (Domozych et al. 2007). As $S$. pygmaeum was isolated from a shallow lake, it is probably a tychoplanktonic species rather than a euplanktonic one. The environmental roles of various EPS compositions are still hard to understand among desmids, especially in plankton. Many advances have been reported in the understanding of the adhesion mechanisms of benthic desmids, and the role of EPSs in such processes is well documented (Domozych et al. 2007, Domozych and Domozych 2008), but the significance of the variations in the Xyl, Fuc, Gal, and uronic acid contents is still obscure and requires further study. S. pygmaeum has a unique feature in its EPS composition, namely, the high content of GlcNAc, which has never been reported before.

In conclusion, our results indicated that photoassimilated carbon excess under limited-nutrient conditions did not increase the EPS production by $S$. pygmaeum, as in other phytoplankton species. This strain degraded photosynthetic pigments to reduce both photosynthetic apparatus damage and nitrogen depletion in the stationary growth phase. Also, alteration of EPS composition during growth was observed only in nutrient-depleted conditions. GlcA content increased as the culture aged, probably due to release of an oligosaccharide or small polysaccharide, enhancing the potential of such polymeric carbohydrates to complex cations. The composition of the larger $S$. pygmaeum EPSs was closer to the EPSs of benthic desmids than of planktonic desmids, and the high GlcNAc content is the first such case reported in desmid carbohydrates.

The authors are indebted to FAPERGS and FAPESP (processes 05/60092.3b0 and 5-51263-5, respectively) for financial support. Also, the authors are grateful to Dr. Maria Jose Dellamano Oliveira for the strain identification.

Abdullahi, A. S., Underwood, G. J. C. \& Gretz, M. R. 2006. Extracellular matrix assembly in diatoms (Bacillariophyceae). V. Environmental effects on polysaccharide synthesis in the model diatom, Phaeodactylum tricornutum. J. Phycol. 42:36378.

Alldredge, A. L., Passow, U. \& Logan, B. 1993. The abundance and significance of a class of large transparent organic particles in the ocean. Deep-Sea Res. Part I Oceanogr. Res. Pap. 40:1131-40.

Barsett, H., Paulsen, B. S. \& Habte, Y. 1992. Further characterization of polysaccharides in seeds from Ulmus glabra Huds. Carbohydr. Polym. 18:125-30.

Biersmith, A. \& Benner, R. 1998. Carbohydrates in phytoplankton and freshly produced dissolved organic matter. Mar. Chem. 63:131-44.

Croasdale, H., Bicudo, C. E. M. \& Prescott, G. W. 1983. A Synopsis of North American Desmids. Part II Desmidiaceae: Placodermae, Section 5: The Filamentous Genera 2-5. University of Nebraska Press, Lincoln, Nebraska, 117 pp.

Domozych, D. S. 2005. The extracellular polymeric substance of the green alga Penium margaritaceum and its role in biofilm formation. Biofilms 2:129-44.
Domozych, D. S. \& Domozych, C. R. 2008. Desmids and biofilms of freshwater wetlands: development and microarchitecture. Microb. Ecol. 55:81-93.

Domozych, D. S., Elliott, L. \& Kiemle, S. N. 2007. Pleurotaenium trabecula, a desmid of wetland biofilms: the extracellular matrix and adhesion mechanisms. J. Phycol. 43:1022-38.

Dubois, M., Guilles, K. A., Hamilton, J. K., Rebers, P. A. \& Smiths, F. 1956. Colorimetric method for determination of sugars and related substances. Anal. Chem. 28:350-6.

Fogg, G. E. 1983. The ecological significance of extracellular products of phytoplankton photosynthesis. Bot. Mar. 26:3-14.

Freire-Nordi, C. S., Vieira, A. A. H. \& Nascimento, O. R. 2005. The metal binding capacity of Anabaena spiroides extracellular polysaccharide: an EPR study. Process Biochem. 40:2215-24.

Giroldo, D., Ortolano, P. I. C. \& Vieira, A. A. H. 2007. Bacterialalgae association in batch cultures of phytoplankon from a tropical reservoir: the significance of algal carbohydrates. Freshw. Biol. 52:1281-9.

Giroldo, D. \& Vieira, A. A. H. 2005. Polymeric and free sugars released by three phytoplanktonic species from a freshwater tropical eutrophic reservoir. J. Plankton Res. 27:695-705.

Giroldo, D., Vieira, A. A. H. \& Paulsen, B. S. 2005. Microbial degradation of extracellular polysaccharides released by a tropical strain of Staurastrum orbiculare (Zygnematophyceae). Phycologia 6:671-7.

Gouvêa, S. P., Vieira, A. A. H. \& Lombardi, A. T. 2002. No effect of $\mathrm{N}$ or $\mathrm{P}$ deficiency on capsule in Staurodesmus converens (Zygnematophyceae, Chlorophyta). Phycologia 41:585-9.

Gremm, T. J. \& Kaplan, L. A. 1997. Dissolved carbohydrates in streamwater determined by HPLC-PAD and pulse amperometric detection. Limnol. Oceanogr. 42:385-93.

Guillard, R. R. L. \& Lorenzen, C. J. 1972. Yellow-green algae with chlorophyllide c. J. Phycol. 8:10-14.

Herndon, J. \& Cochlan, W. P. 2007. Nitrogen utilization by the raphidophyte Heterosigma akashiwo: growth and uptake kinetics in laboratory cultures. Harmful Algae 6:260-70.

Kiemle, S. N., Domozych, D. S. \& Gretz, M. R. 2007. The extracellular polymeric substances of desmids (Conjugatophyceae, Streptophyta): chemistry, structural analyses and implications in wetland biofilms. Phycologia 46:617-27.

Lombardi, A., Vieira, A. A. H. \& Sartori, A. L. 1998. Extracellular carbohydrate production by Micrasterias furcata (Desmidiaceae) grown in various nitrate concentrations. Hoehnea 25:1-9.

Mackinney, G. 1951. Absorption of light by chlorophyll solutions. J. Biol.Chem. 140:315-22.

Myklestad, S. M. 1995. Release of extracellular products by phytoplankton with special emphasis on polysaccharides. Sci. Total Environ. 165:155-64.

Padisák, J. 2004. Phytoplankton. In Reynolds, C. S. \& O'Sullivan, P. E. [Eds.] The Lakes Handbook. Blackwell Publishing, Oxford, UK, pp. 251-98.

Passow, U. 2002. Production of transparent exopolymer particles (TEP) by phyto- and bacterioplankton. Mar. Ecol. Prog. Ser. 236:1-12.

Passow, U., Alldredge, A. L. \& Logan, B. E. 1994. The role of particulate carbohydrate exudates in the flocculation of diatom blooms. Deep-Sea Res. Part I Oceanogr. Res. Pap. 41:5-57.

Paulsen, B. S. \& Vieira, A. A. H. 1994. Structural studies on extracellular dissolved and capsular polysaccharides produced by Spondylosium panduriforme. J. Phycol. 30:638-41.

Press, W. H., Teukolsky, S. A., Vetterling, W. T. \& Flannery, B. P. 1993. Numerical Recipes in C: The Art of Scientific Computing. Cambridge University Press, New York, 994 pp.

Reinhold, V. N. 1972. Gas-liquid chromatographic analysis of constituent carbohydrates in glycoproteins. Methods Enzymol. 25:244-9.

Reynolds, C. S. 2007. Variability in the provision and function of mucilage in phytoplankton: facultative responses to the environment. Hydrobiologia 578:37-45.

Reynolds, C. S., Huszar, V., Kruk, C., Naselli-Flores, L. \& Melo, S. 2002. Towards a functional classification of the freshwater phytoplankton. J. Plankton Res. 24:417-28. 
Salmaso, N. \& Padisak, J. 2007. Morpho-functional groups and phytoplankton development in two deep lakes (Lake Garda, Italy and Lake Stechlin, Germany). Hydrobiologia 578:97-112.

Smith, D. J. \& Underwood, G. J. C. 2000. The production of extracellular carbohydrates by estuarine benthic diatoms: the effects of growth phase and light and dark treatment. J. Phycol. 36:321-33.

Vieira, A. A. H., Giroldo, D. \& Ortolano, P. I. C. 2006. Aggregate formation in axenic and microbial co-inoculated batch cultures of Aulacoseira granulata (Bacillariophyceae). Acta Limnol. Brasiliensia 18:1-7.

Vieira, A. A. H. \& Klaveness, D. 1986. The utilization of organic nitrogen-compounds as sole nitrogen-source by some freshwater phytoplankters. Nord. J. Bot. 6:93-7.

Vieira, A. A. H. \& Myklestad, S. 1986. Production of extracellular carbohydrate in cultures of Ankistrodesmus densus. J. Plankton Res. 8:985-94.
Vieira, A. A. H., Ortolano, P. I. C., Giroldo, D., Dellamno-Oliviera, M. J., Bittar, T. B., Lombardi, A. T., Sartori, A. L. \& Paulsen, B. S. 2008. Role of hydrophobic extracellular polysaccharide of Aulacoseira granulata (Bacillariophyceae) on aggregate formation in a turbulent and hypereutrophic reservoir. Limnol. Oceanogr. 53:1887-99.

Vieira, A. A. H. \& Paulsen, B. S. 1994. Studies on the composition of extracellular polysaccharide produced by Hyalotheca dissiliens (Desmidiales). Biol. (Bratisl.) 49:535-8.

Wicks, R. J., Moran, M. A., Pittman, L. J. \& Hodson, R. E. 1991. Carbohydrates signatures of macrophytes and their dissolved degradation products as determined by a sensitive high-performed ion chromatography method. Appl. Environ. Microb. $57: 3135-43$

Wood, A. M. \& Van Valen, L. M. 1990. Paradox lost? On the release of energy-rich compounds by phytoplankton. Mar. Microb. Food Webs 4:103-16. 
This document is a scanned copy of a printed document. No warranty is given about the accuracy of the copy. Users should refer to the original published version of the material. 